\title{
Editorial for EAIT issue 5, 2019
}

\section{Arthur Tatnall $^{1}$}

Published online: 13 August 2019

(C) Springer Science+Business Media, LLC, part of Springer Nature 2019

Education and Information Technologies (EAIT) is the official journal of the IFIP Technical Committee on Education (TC3) and covers the complex relationships between information and communication technologies and education, from the micro of specific applications or instances of use in classrooms to macro concerns of national policies and major projects; from classes of five year olds to adults in tertiary institutions; from teachers and administrators, to researchers and designers; from institutions to open, distance and lifelong learning. The journal's breadth of coverage allows EAIT to examine fundamental issues at all levels, discuss specific instances and cases, draw inference and probe theory. This journal is embedded in the research and practice of professionals.

To begin this issue is an article by Mustafa Serkan Günbatar (Van Yüzüncü Y1l University, Turkey) titled: Computational thinking within the context of professional life: Change in CT skill from the viewpoint of teachers. The reported study, conducted in Turkey, aimed to compare in-service and pre-service teachers' computational thinking (CT) skills and to take in-service teachers' opinions about the contribution of professional life to differentiation in this skill. The study found that in-service teachers are significantly different from pre-service teachers according to the common effect of the sub-dimensions of CT skill.

Applying the technology acceptance model to understand maths teachers' perceptions towards an augmented reality tutoring system is next. It comes from Emin Ibili (Afyonkarahisar Health Sciences University, Turkey) and Dmitry Resnyansky and Mark Billinghurst (The University of South Australia, Australia). In their paper they examine mathematics teachers' level of acceptance and intention to use the Augmented Reality Geometry Tutorial System (ARGTS), a mobile Augmented Reality (AR) application developed to enhance students' 3D geometric thinking skills. In their study, ARGTS was shared with mathematics teachers who were then surveyed using the Technology Acceptance Model (TAM) to understand their acceptance of the technology. Also examined were the external variables of Anxiety, Social Norms and Satisfaction as well as the effect of the gender, degree of graduate status and number of years

Arthur Tatnall

Arthur.Tatnall@vu.edu.au

1 Victoria University, Melbourne, Australia 
of teaching experience. The study found that Perceived Ease of Use (PEU) had a direct effect on the Perceived Usefulness (PU) in accordance with TAM.

The following paper: $A$ new trend in preparing for foreign language exam (YDS) in Turkey: Case of WhatsApp in mobile learning was contributed by: Mustafa Saritepeci (Necmettin Erbakan University, Turkey), Ali Duran (Gazi University, Turkey) and Uğur Ferhat Ermiş (Amasya University, Turkey). The reported study sought to reveal perceptions towards the employment of WhatsApp in foreign language learning, especially preparing for a national academic language exam. During the preparation for an academic exam called Foreign Language Exam (YDS), WhatsApp was included as a learning community to reinforce the activities conducted in regular classrooms. Findings indicated that according to the participant's views, WhatsApp supported foreign language activities provided active learning, continuity of learning, learner-instructor interaction, learner satisfaction and motivation to learn foreign languages.

Chijioke Jonathan Olelewe, Emmanuel E. Agomuo and Peter Uzochukwu Obichukwu (all from University of Nigeria) next offer: Effects of B-learning and F2F on college students' engagement and retention in QBASIC programming. They begin by asserting that achieving learner engagement in the teaching and learning process is paramount towards ensuring knowledge retention in QBASIC programming. Their study focused on the effects of b-learning and face-to-face (F2F) on college students' engagement and retention in QBASIC programming. Their results showed that the treatment groups' retention mean score was significantly higher than the control group and that b-learning facilitated college students' engagement and improved knowledge retention in QBASIC programming compared to their counterparts in the F2F group.

The following paper deals with internship training and is by Rayed AlGhamdi (King Abdulaziz University, Kingdom of Saudi Arabia). Fostering information technology students' internship program notes that improving the internship training program is critical for students. This internship is the only requirement in the current IT curriculum that attempts to build a connection bridge for students, and a solid bridge is expected to maximize the confidence of students in regard to discovering their future career opportunities in the Saudi Arabian market. The main objective of the research was to explore the skills gap between IT internship students and leaders in the IT industry.

Prediction of academic achievements of vocational and technical high school (VTS) students in science courses through artificial neural networks (comparison of Turkey and Malaysia) by Ali Yağci and Mustafa Çevik (Karamanoglu Mehmet Bey University, Turkey) describes a study that aimed to predict the academic achievements of Turkish and Malaysian vocational and technical high school (VTS) students in science courses (physics, chemistry and biology) through artificial neural networks and to find measures to be taken against their failure. At the end of the study, a successful academic achievement prediction system was developed, and measures to be taken were determined in order the prevent failure of students.

Can differences in learning preferences be attributed to the differences in individuals' cognitive capacities which may lead them to undertake certain behaviour? In their paper: The effectiveness of an online learning system based on aptitude scores: An effort to improve students' brain activation, Atef Eldenfria (Misurata University, Libya) and Hosam Al-Samarraie (Universiti Sains Malaysia, Malaysia) argue that 
characterising the learning complexity based on the volume of information presented to learners can eliminate any avoidable load on working memory, and their reported study examined the effectiveness of an online continuous adaptive mechanism (OCAM) based on changes in learner aptitude scores across learning sessions. Their results showed that OCAM helped learners to understand the content being presented according to their aptitude scores, thus improving their brain activation.

Problem solving skills are considered an integral part of grasping the precise concepts of the programming domain for novices in introductory programming courses say Sohail Iqbal Malik, Roy Mathew and Rim Al-Nuaimi (Buraimi University College, Oman), Abir Al-Sideiri (Buraimi University College, Oman and Universiti Tenaga National (UniTen), Malaysia) and Jo Coldwell-Neilson (Deakin University, Australia) in their article: Learning problem solving skills: Comparison of E-learning and $M$ learning in an introductory programming course. But, they note, these skills are mostly covered only in early lectures of such courses or are included in just a few early chapters of some relevant textbooks resulting in often reported high failure and dropout rates. In their study they developed and introduced an application called PROBSOL, which is designed to focus on, and enhance, novice programmers' problem solving skills, in two versions: a web-based version and a mobile app. The results show that both students and instructors appreciated the applications and that their use supports students' cognitive gains and engagement. However, students preferred the mobile version rather than the web-based version.

Students' behavior mining in e-learning environment using cognitive processes with information technologies by Ahmad Jalal and Maria Mahmood (Air University, Pakistan) comes next. They argue that traditional learning practices are being replaced with webinars (live online classes), e-Quizes (online testing) and video lectures for effective learning and performance evaluation and these e-learning methods use sensors and multimedia tools to contribute in resource sharing, social networking, interactivity and corporate trainings. This paper presents hybrid spatio-temporal features for a student behaviour recognition system that recognizes student-student behaviours from sequences of digital images and segments student silhouettes using neighbouring data point observation and extracts co-occurring robust spatio-temporal features having full body and key body points techniques.

The next paper: Enhancing ICT for quality education in sub-Saharan Africa by Simplice A. Asongu and Nicholas M. Odhiambo (University of South Africa) assesses the relevance of information and communication technology in primary education quality in a panel of 49 Sub-Saharan African countries for the period 2000-2012. The empirical evidence is based on Two Stage Least Squares and Instrumental Quantile Regressions and found that: mobile phone and internet penetration rates reduce poor quality education. It follows that enhancing internet penetration will benefit countries with above-median levels of poor education quality while enhancing internet penetration is not immediately relevant to reducing poor education quality in countries with below-median levels of poor education quality.

Seyed Mohammadbagher Jafari and Zahra Abdollahzade (University of Tehran, Iran) then present: Investigating the relationship between learning style and game type in the game-based learning environment. They argue that using computer games to improve performance and learning is a new field which can be used as a powerful educational tool. New games to fit the learning styles of each individual can be made to 
have a customized learning environment. Currently, playing computer games has become far more widespread among Iranian youth and teenagers who are mostly students.

The next paper investigates internet addiction, among college students in terms of causes and effects. Internet addiction among college students: Some causes and effects comes from Meltem Huri Baturay and Sacip Toker (Atılım University, Turkey). Antecedent variables they examined are: game addiction, bad relationships with friends, family and professors, neglecting daily chores, hindrance of sleep pattern, use internet for researching, weekly internet use hours, leisure time activities, reading and playing computer games. Consequence variables were self-esteem, self-confidence, social self-efficacy, loneliness, and academic self-efficacy. The results indicates that game addiction, neglecting daily chores, bad relationships with professors are significantly associated with internet addiction.

Investigation of Turkish preservice teachers' intentions to use IWB in terms of technological and pedagogical aspects is by Salih Bardakc1 and Muhammet Fatih Alkan (Tokat Gaziosmanpaşa University, Turkey), and investigated the technological and pedagogical constructs underlying Turkish preservice teachers' behavioural intentions to use interactive whiteboard (IWB) based on the UTAUT model and TPACK, using three structural equation models: technological framework, pedagogical framework and integrated model. Their findings showed that performance expectancy and technological pedagogical knowledge were the variables that significantly influenced the behavioural intention to use IWB in technological and pedagogical frameworks, respectively.

Collaborative digital textbooks - a comparison of five different designs shaping teaching and learning notes that Collaborative Digital Text Books (cDTB) are emerging artefacts in Swedish schools, combining the quality assured content of traditional paper and digital text books with affordances for multimodal representation of knowledge, differentiated instruction, communication, collaboration, documentation and with varying learning activities. The authors: Anna-Lena Kempe (Stockholm University, Sweden) and Åke Grönlund (Örebro University, Sweden) analysed and compared design features in five brands on the market 2017. The analytic comparison indicated that the studied cDTB are built on differing notions of how knowledge is represented as well as on how learners and teachers were supposed to engage with the content.

The next paper examines the effectiveness of programming in pairs in the Scratch environment in primary school, and is from Olivera Iskrenovic-Momcilovic (University of Novi Sad, Serbia). Pair programming with scratch points out the successful use of Scratch as a learning environment for any students of programming and that analysis has shown that programming in pairs produces better results for beginners in comparison to programming as an individual student. The reported research showed that results are positively correlated with the students' general school success and show that there are no differences in achievement between boys and girls.

Soultana Karga and Maya Satratzemi (University of Macedonia, Greece) point out, in their paper: Using explanations for recommender systems in learning design settings to enhance teachers' acceptance and perceived experience, that the reuse of Learning Designs can bring significant advantages to the educational community, such as the diffusion of best teaching practices and the improvement of teaching quality and learning outcomes. Their paper investigates the results of providing explanations for 
Learning Design recommendations to teachers as although various tools, including Recommender Systems, have been developed to implement the notion of reusing Learning Designs, their adoption by teachers falls short of expectations. They describe the design and implementation of an explanatory mechanism incorporated into a Recommender System, which proposes pre-existing Learning Designs to teachers.

Investigating the effects of the flipped classroom model on Omani EFL learners' motivation level in English speaking performance by Mohamad Yahya Abdullah (Universiti Kebangsaan Malaysia and Buraimi Univeristy College, Sultanate of Oman), Supyan Hussin (Universiti Kebangsaan Malaysia) and Kemboja Ismail (Universiti Kebangsaan Malaysia) indicates that Oman has moved towards student-centred instructional design, especially in higher education, and that this is facilitated by emerging technology. Their study showed that using Flipped Classroom Model (FCM) as a teaching approach helped to develop a creative, engaging, and motivating climate in the EFL speaking class. The Omani EFL students showed significantly greater inclination to be involved in the speaking activities over time, including their interest in applying FCM in all taught courses.

To E-textbook or not to E-textbook? A quantitative analysis of the extent of the use of E-textbooks at Ajman University from students' perspectives was contributed by: Sami Al-Qatawneh, Najeh Alsalhi, Ahood Al Rawashdeh, Tizreena Ismail and Khaled Aljarrah (Ajman University, UAE). They point out that in an age of globalization and rapid technological development the United Arab Emirates is committed to merging technology into all higher education institutions. The purpose of their study was to identify the degree to which e-textbooks are used at Ajman University from a student perspective, and found that students there use e-textbooks to a high degree. Their research showed that the degree of use varied according to gender (with females being more likely to use them), college type (with Dentistry College students being most likely), and according to year of study (with those in their fifth academic year being most likely).

Using digital technology effectively in schools requires profound changes in traditional teaching and learning activities say Annika Agélii Genlott and Åke Grönlund (Örebro University School of Business, Sweden) and Olga Viberg (Royal Institute of Technology, Sweden) in their article: Disseminating digital innovation in school leading second-order educational change. They point out that pedagogical innovations often start small-scale, and developing good ideas into shared practice across schools is challenging in many ways, especially if the innovation requires second-order change. Their study investigated how a validated pedagogical method requiring integrated ICT use and second-order change can be disseminated and sustained over time, and found that organized teacher development programs can drive second-order change, but that this requires considerable, active, and sustained effort from leaders at both school and district level.

Joseph Njiku, Jean Francois Maniraho and Védaste Mutarutinya (University of Rwanda) then present: Understanding teachers' attitude towards computer technology integration in education: A review of literature. Their article presents an exploration of teachers' attitude towards technology survey scales from multiple studies, a review of literature on the development of survey scales. They found that enjoyment, confidence, anxiety and teachers' position towards technology integration were the most common constructs. 
In Social networking and academic performance: A net benefits perspective, Tenzin Doleck, Susanne P. Lajoie and Paul Bazelais (McGill University, Canada) suggest that the effect of social networking site (SNS) use is especially significant for students, as they tend to be the most frequent and heavy users of such platforms. Prior research has documented the links between SNS use and academic performance, but empirical evidence is inconclusive.

A case study: Views on the practice of opting in and out of lecture capture by Eleanor J. Dommett, Wijnand van Tilburg and Benjamin Gardner (King's College London, UK) points out that lecture capture use has increased in recent years, and that although research shows that staff and students view capture differently, their views on the practice of opting-in and out has not been previously investigated, even though this element of practice can be specified in institutional policy and governance. Focus groups revealed that staff members were unclear on issues around consent. Both staff and students felt that staff should determine whether to capture their lectures, although students felt opting-out should require approval from senior staff. Survey data showed the two groups differed in policy preference, with student's preferring Opt-out and staff wanting Opt-in, and in terms of whether approval should be needed to opt-out.

Although a number of studies have reported on the positive effects of Mobile Assisted Language Learning in the development of students' language learning, few studies have examined language assessment, particularly Dynamic Assessment, in this area. In their study: The impact of mobile-based dynamic assessment on improving EFL oral accuracy, Abbas Ali Rezaee, Seyyed Mohammad Alavi and Parisa Razzaghifard (University of Tehran, Iran) aimed to investigate the effect of Mobilebased Dynamic Assessment (MDA) on English as a Foreign Language (EFL) learners' oral accuracy. Their research showed that the experimental groups who received MDA significantly outperformed the control group on the post-test. The findings point to the effectiveness of MDA in the development of EFL students' oral accuracy.

Automated system for evaluating higher education programs describes research by Mohamed Adel Serhani, Salah Bouktif, Nabeel Al-Qirim and Hadeel T. El Kassabi (United Arab Emirates University, UAE). Program review is recognized as a common practice amongst universities worldwide as this ensures that programs are up to date, meet high quality standards, continuously respond to changes and adhere to continuous improvement practices. They note that managing such multi-process program evaluation could be enhanced using an automated system that streamlines the different processes and provides more cost-effective management and coordination activities, but that the literature indicates that very few automation efforts have been implemented to support such review management systems. In their paper they highlight the cost effectiveness of the different main activities and processes involved in the programs review lifecycle, and propose a software tool design called Automated Program Review Management System (APRMS) to support and manage the program review process.

Renato Cortinovis, Alexander Mikroyannidis, John Domingue, Paul Mulholland and Robert Farrow (The Open University, UK) next present: Supporting the discoverability of open educational resources. They point out that Open Educational Resources (OERs), now available in large numbers, have a considerable potential to 
improve many aspects of society, yet one of the factors limiting this positive impact is the difficulty to discover them. Their study investigated and proposed strategies to better support educators in discovering OERs, mainly focusing on secondary education. Following the Design Science Research methodology, three prototypes to support as well as to refine these tasks were iteratively designed, implemented, and evaluated involving an increasing number of educators in usability oriented studies.

M-learning adoption in the Arab gulf countries: A systematic review of factors and challenges is by Ahmed Alsswey and Hosam Al-Samarraie (Universiti Sains Malaysia, Malaysia). They note that integration of mobile technology in a university context has been found to provide a superior learning environment compared to the traditional classroom lecture, but that there are several challenges that may delay the adoption of m-learning and postpone the revolution it promised. Their paper identifies the influential factors affecting m-learning adoption among students in Arab Gulf universities.

Ward Peeters (Kanda University of International Studies, Japan and University of Antwerp, Belgium) then presents: The peer interaction process on Facebook: a social network analysis of learners' online conversations. As little quantitative research has been performed on the ways in which learners interact with one another via online peer interaction opportunities on social media platforms for academic purposes, little is known about how learners develop a network of peers and how they interact with this peer group through social media tools. This paper analyses the peer interaction process in a Facebook environment, integrated into the foreign language curriculum at university level. The study showed how learners can develop both their learning and language ability as a scaffolded, dialogic process within an online social networking environment when having access to a combination of information and learning resources.

The technology acceptance model, and extensions of it, suggests a causal relationship between the perceived ease of use and usefulness of an information technology system. Re-examining the relationship between ease of use and usefulness for the next generation from Michael Sheppard and Conor Vibert (Acadia University, Canada) compared competing structural equation models of technology acceptance. They found that while ease of use is important it does not determine perceived usefulness. Tasktechnology fit is, however, a direct causal antecedent of perceived usefulness and this relationship is modified by perceived ease of use. The results of this study suggest that technology acceptance models may need to be revised to consider changes in users' perceptions and behaviour related to the use of mobile computing technology and current software development practices.

The final paper in this issue: Innovation and communication technologies: Analysis of the effectiveness of their use and implementation in higher education comes from Elena A. Tokareva, Yulia V. Smirnova and Larisa G. Orchakova (Moscow City University, Russian Federation). In their reported research, they developed and conducted a survey to determine the quality of implementation and organisation of ICT from the point of view of university students. The study was conducted in two groups of students, intramural and extramural, to identify a common problem of domestic education. The survey focused on a student view of education programme 
innovativeness, teachers' participation in the ICT introduction and the technological support in selected universities.

Papers in this issue come from: Turkey, Australia, Nigeria, Kingdom of Saudi Arabia, Libya, Malaysia, Sultanate of Oman, Pakistan, South Africa, Iran, Sweden, Serbia, Greece, UAE, Rwanda, UK, Canada, Russian Federation, Japan and Belgium.

\section{Arthur Tatnall}

Editor-in-Chief

Publisher's note Springer Nature remains neutral with regard to jurisdictional claims in published maps and institutional affiliations. 